\title{
Jogos de computador como estratégia de ensino de vocabulário de língua inglesa
}

\author{
Ana Maria Zanoni da Silvai
}

\section{RESUMO}

Este trabalho demonstra os resultados de uma pesquisa realizada com alunos do quarto ano do ensino fundamental da escola Municipal Vicente de Paula, localizada em Frutal/MG. A pesquisa teve por objetivo trabalhar a aquisição de vocabulário em língua inglesa por meio de jogos de computador disponíveis na internet e foi embasada nos estudos de Huizinga (2007), Kishimoto (1998), Vygotsky (1988) e Krashen (1982). A seleção dos jogos ocorreu por meio de uma pesquisa exploratória em sites na internet e levou em consideração aspectos como a interação entre o aluno, o computador e o jogo, o conteúdo lexical, a visibilidade da ação e a autocorreção. Nesse sentido, optou-se pelos jogos: Word Search, Memory Game, Number Race. Os resultados do trabalho com jogos mostraram a criação de contextos significativos nos quais houve a aproximação do aluno com o uso concreto do idioma, a reflexão sobre o sistema alfabético, a correspondência grafo-fônica e o exercício das habilidades de listening, writing $e$ speaking de forma prazerosa e reflexiva.

Palavras-chave: Ensino de língua inglesa; Aquisição de vocabulário; Jogos de computador.

\begin{abstract}
This work demonstrates the results of a research carried out with students of the fourth year of elementary school at the Vicente de Paula Municipal School, located in Frutal/MG. The research aimed to work on the acquisition of vocabulary in English through computer games available on the internet and was based on the studies of Huizinga (2007), Kishimoto (1998), Vygotsky (1988) and Krashen (1982). The selection of games occurs through an exploratory research on websites on the Internet and took into account aspects such as the interaction between the student, the computer and the game, the lexical content, the visibility of the action and self-correction. In this sense, we opted for games, such as Word Search, Memory game, Number race. The results show the creation of meaningful contexts in which there was an approach of the student with a concrete use of the language, the reflection on the alphabetical system and the graphical-phonic correspondence and the exercise of listening, writing and speaking skills in a pleasant and reflective way.
\end{abstract}

Keywords: English language teaching; Vocabulary acquisition; Computer games.

\footnotetext{
${ }^{i}$ Doutora em Estudos Literários pela FCLAR/UNESP. Professora efetiva no Instituto Municipal de Ensino Superior de Bededouro. Desenvolve pesquisa nas áreas de literaturas e ensino de Língua Inglesa. https://orcid.org/0000-0002-6655-0748 | anazanoni_@hotmail.com
} 


\section{INTRODUÇÃO}

O trabalho com a disciplina de Língua Inglesa Instrumental para alunos de cursos de graduação trouxe à tona a experiência dos discentes com o processo de ensino e de aprendizagem desse idioma, por eles vivenciada durante a trajetória no ensino fundamental e médio. No decorrer das aulas, empiricamente, constatou-se que as atividades de ensino calcadas no método tradicional e no uso de livros didáticos nem sempre se mostram atraentes ou motivadoras para tais alunos, pois notava-se a carência de vocabulário e de conhecimento de aspectos gramaticais basilares.

O desnivelamento dos graduandos despertou o interesse e motivou a realização de uma pesquisa focada na busca por alternativas e materiais pedagógicos capazes de contribuírem para a melhoria do ensino-aprendizagem de língua inglesa, principalmente, no ensino fundamental. A escolha desse público-alvo se deve ao fato de que, geralmente, é nas séries iniciais que o aluno tem o primeiro contato formal com esse idioma. Portanto, trata-se de um momento oportuno para a inserção de atividades lúdicas como, por exemplo, jogos que sejam capazes de favorecerem a assimilação de palavras e a ampliação de vocabulário, por meio de um contexto no qual a aprendizagem ocorra de forma mais prazerosa e atrativa. Nesse sentido, foi delineado o projeto denominado de "Laboratório de Idiomas", cujo objetivo principal era a seleção e organização de materiais, sobretudo jogos disponibilizados gratuitamente na internet, que pudessem contribuir como ferramentas pedagógicas favoráveis ao ensino e à aprendizagem de vocabulário de língua inglesa, bem como oferecer aulas desse idioma a alunos do quarto ano do ensino fundamental.

Para desenvolver os objetivos do projeto, no decorrer do ano de 2017, firmou-se uma parceria com a Escola Municipal Vicente de Paula, localizada na cidade de Frutal/MG, a fim de oferecer aulas de língua inglesa a alunos do quarto ano do ensino fundamental, os quais ainda não haviam travado conhecimento formal com o idioma. A ausência de contato formal com a língua inglesa era relevante, porque seria possível propiciar a esses alunos situações de aprendizagem de vocabulário de forma lúdica e, sobretudo, por ter a oportunidade de verificar na prática aspectos positivos e negativos do processo sem que houvesse a interferência de conhecimentos prévios em relação ao idioma em apreço. 
A escolha do público alvo ocorreu em virtude da importância do conhecimento linguístico diversificado na preparação do aluno para o exercício da cidadania e desempenho profissional. Ademais, a inclusão da língua estrangeira no Currículo do Ensino Fundamental foi estabelecida pela Lei no 9.394/97, Art.26, parágrafo 50: "Na parte diversificada do currículo será incluído, obrigatoriamente a partir da quinta série, o ensino de pelo menos uma língua estrangeira moderna, cuja escolha ficará a cargo da comunidade escolar dentro das possibilidades da instituição" (BRASIL, 1997, p. 26). Com a atual redação dada pelo parágrafo quinto da Lei $n^{\circ} 13.415 / 2017$, a inclusão de uma segunda língua deve ser a partir do sexto ano e, portanto, aos alunos das séries iniciais não são oferecidos conteúdos de língua estrangeira.

A opção pelo trabalho com jogos foi motivada pelo fato de Leffa (1988) chamar a atenção para a carência de reflexão a respeito de metodologias de ensino de línguas estrangeira, pois nem sempre elas, por si só, promovem a aprendizagem. Nesse sentido, optou-se pelo uso de jogos oriundos das tecnologias de informação como uma das estratégias de ensino-aprendizagem a ser adotada em sala, com o objetivo de despertar o gosto pela aquisição de vocabulário de língua inglesa.

\section{OS JOGOS NO PROCESSO DE ENSINO-APRENDIZAGEM DE LÍNGUA INGLESA}

Na concepção de Huizinga (2007), a palavra jogo adquire diferentes conotações de acordo com as tradições culturais do local em que ela é empregada, podendo ser usada em sentido lúdico, de trabalho, de luta e de conflito. O jogo é um elemento que faz parte da cultura humana que, segundo o autor, é:

\footnotetext{
Uma atividade ou ocupação voluntária exercida dentro de certos e determinados limites de tempo e de espaço, segundo regras livremente consentidas, mas absolutamente obrigatórias, dotadas de um fim em si mesmo, acompanhado de um sentimento de tensão e alegria e de uma consciência de ser diferente de "vida cotidiana". (HUIZINGA, 2007, p.33)
}

Kishimoto (1988, p. 106) também chama atenção para fato de que a variedade dos fenômenos considerados como jogos dificultam a definição do vocábulo, pois tratase de um termo que "assume a imagem, o sentido que cada sociedade lhe atribui. É este o aspecto que nos mostra por que, dependendo do lugar e da época, os jogos assumem significações distintas”. 
Os jogos sempre estiveram presentes na história da humanidade e a utilização deles como uma ferramenta promovedora da aprendizagem e de conteúdos específicos não é nova. Na antiguidade, Platão, por exemplo, já defendia o jogo como um meio de aprendizagem prazerosa e significativa, capaz de promover a assimilação dos conteúdos de diferentes disciplinas de forma lúdica. Durante o período medieval, o uso de jogos foi considerado como uma atividade deleitosa, porém, no século XIV, o lúdico foi incorporado ao processo de formação de jovens e crianças, tal como afirma Lima (2008).

Segundo Kishimoto (1998), a partir do século XVIII, o jogo passou a ser visto como uma atividade séria e favorável à promoção da educação. A inclusão de jogos no processo de aprendizagem motivou estudiosos como, por exemplo, Piaget (1998, p.158), a refletir sobre o tema e a afirmar que os jogos propiciam a consolidação de esquemas já formados e despertam o prazer, pois "não são apenas uma forma de desafogo ou entretenimento para gastar energias das crianças, mas meios que contribuem e enriquecem o desenvolvimento intelectual".

Para Vygotsky (1988), as atividades lúdicas atuam no desenvolvimento, uma vez que o ato de jogar aguça a curiosidade, amplia o desenvolvimento da linguagem, do pensamento e da concentração porque : "Ao brincar, a criança assume papéis e aceita as regras próprias da brincadeira, executando, imaginariamente, tarefas para as quais ainda não está apta ou não sente como agradáveis na realidade"( VYGOTSKY, 1988, p. 104).

A inserção de jogos como ferramenta pedagógica também é apontada por Kishimoto (1994) como uma prática profícua ao aprendizado, uma vez que:

O jogo como promotor da aprendizagem e do desenvolvimento, passa a ser considerado nas práticas escolares como importante aliado para o ensino, já que colocar o aluno diante de situações lúdicas como jogo pode ser uma boa estratégia para aproximá-lo dos conteúdos culturais a serem veiculados na escola. (KASHIMOTO, 1994, p. 13)

Com o desenvolvimento das tecnologias de informação, o lúdico ganhou novos brinquedos, entre eles, os jogos disponibilizados por meio do computador. O avanço da tecnologia possibilitou a criação de jogos computacionais educativos, por meio dos quais se une o prazer de jogar com ações voltadas para o ensino-aprendizagem de conteúdos específicos como o de outros idiomas, por exemplo. Porém, ao se mencionar a expressão jogos educativos, alguns questionamentos vêm à tona: Qual a diferença entre um jogo educativo e os demais? Quais critérios norteiam a seleção de jogo com 
fins pedagógicos? Como associar os conteúdos de língua inglesa com as etapas de um jogo?

O jogo com fins educativos foi consolidado no século XVI, como "suporte da atividade didática, visando à aquisição de conhecimentos", ou seja, como um facilitador das tarefas de ensino (KISHIMOTO, 1998, p. 17). Porém, segundo Kishimoto (1998), atualmente o significado de jogo, na educação, vincula-se a funções lúdicas e educativas. Ao jogar, o aluno sente prazer e, ao mesmo tempo, adquire novos conhecimentos sobre um dado tema. Cabe ressaltar a necessidade de se dosarem ambas as funções, uma vez que o jogo não pode restringir-se apenas à aprendizagem e tão pouco ao lúdico. Na educação, os jogos são usados com fins distintos e, conforme afirma Kishimoto (1998), denominam-se de jogos didáticos aqueles cujos objetivos são a aquisição de conteúdos específicos. Já os educativos são os jogos mais dinâmicos, que envolvem com maior frequência as ações dos alunos.

A classificação proposta por Kishimoto encontra-se apoiada no critério de finalidade do trabalho a ser realizado com os jogos. Sendo assim, para que o trabalho com jogos, cuja finalidade venha ser a de aquisição de uma segunda língua, seja bemsucedido, faz-se necessário atentar para a distinção entre os termos aprendizagem e aquisição proposta por Krashen (1982) e Leffa (2016). Segundo os autores, a aprendizagem de uma língua ocorre de modo formal e consciente, por meio da explicitação de regras. Já a aquisição ocorre informalmente através de situações reais sem que haja esforço consciente. Em uma situação de aprendizagem, portanto, uma palavra ou enunciado pode ser produzido em língua materna e de modo consciente passar para a língua-alvo, porém, na aquisição, o enunciado ou palavra se origina diretamente na língua-alvo.

Ainda segundo Krashen (1992), para que ocorra a assimilação de uma segunda língua é preciso que haja o desenvolvimento de quatro habilidades: a audição, a oralidade, a escrita e a leitura. Trabalhar as quatro destrezas não é uma tarefa fácil, pois requer a adoção de uma abordagem de ensino que favoreça o desenvolvimento da competência comunicativa, para que o aluno consiga se comunicar adequadamente em diferentes situações comunicativas, valendo-se da língua-alvo.

Embora Krashen (1982) ressalte que tal distinção entre aquisição e aprendizagem não se aplica exclusivamente à aquisição de uma outra língua, no 
trabalho com jogos didáticos ela se torna relevante. Ao jogar, o aluno entra em contato direto com palavras, expressões e frases da língua-alvo, faz uso da linguagem para se comunicar e trabalha as quatro habilidades sem ter ciência de que está adquirindo uma segunda língua. Dessa forma, a aquisição ocorre de maneira subconsciente.

O modo como o processo de ensino-aprendizagem ocorre constitui um aspecto importante. Ao abordar as dificuldades de se ensinar língua estrangeira, Costa chama a atenção para este aspecto ao afirmar que: "A questão reside, portanto, não no fato de que devemos ou não ensinar uma Língua Estrangeira na escola, cuja resposta parece-nos óbvia, mas outros pontos, como a maneira em que este ensino é efetuado" (COSTA, 1987, p. 2). Para Wright; Betteridge; Buckby (1998), aprender uma língua é um trabalho árduo que requer esforço para entender e repetir tanto na oralidade quanto na escrita a linguagem recém compreendida. Os autores apontam que uma forma de manter o interesse do aluno é através de jogos. Eles concebem o jogo como uma atividade divertida, envolvente, desafiadora e capaz de auxiliar o professor na criação de contextos, nos quais a linguagem é útil e significativa. Por meio de jogos, os alunos experimentam a linguagem e não apenas a estudam.

O trabalho com jogos pode ser uma estratégia de ensino favorável ao processo de ensino-aprendizagem de vocabulário de língua inglesa, uma vez que este é considerado por de Schimitt (2000) como um elemento chave para aprender outra língua. Os jogos cujo grau de dificuldade esteja em consonância com o nível de conhecimento da língua-alvo, podem contribuir para a construção de um inventário linguístico, a partir de ações vivenciadas de forma lúdica. Ao jogar, o aluno constrói tanto um inventário linguístico composto por frases, expressões idiomáticas, sentenças e demais palavras associadas ao tema em torno do qual o jogo foi desenvolvido, quanto conhecimentos extras a respeito da cultura da língua-alvo e também de outras áreas do saber.

Nesse sentido, para desenvolver atividades com jogos é preciso realizar uma seleção do material, a fim de promover situações favoráveis à aquisição de um conteúdo específico e, como afirma Leffa (2016), tal seleção requer análise, desenvolvimento, implementação e avaliação. No decorrer da análise, deve-se levar em consideração o conhecimento prévio do aluno, para que o material escolhido esteja adequado tanto ao conhecimento quanto ao conteúdo a ser devolvido. Durante essa etapa é necessário não 
apenas "estabelecer o total das competências a serem desenvolvidas, mas também descontar dessas competências o que o aluno já domina. O saldo dessa operação é o que o aluno precisa aprender” (LEFFA, 2016, p. 106).

Após a análise das necessidades, é importante definir os objetivos pretendidos com a atividade a ser realizada com o material. Ter objetivos claramente definidos permite ao discente saber o que está sendo esperado dele e ajuda a verificar se o material favorece ou não o ensino. Já na implementação, o foco recai sobre quem fará o uso do material selecionado: se será o próprio professor, outro professor ou o aluno sem a presença de um docente, como afirma Leffa (2016). Quanto à avalição, esta pode se dar de modo informal ou formal. A avaliação informal pode ser feita, por exemplo, por meio da observação direta do trabalho do estudante com o material, enquanto na formal busca-se saber o que os alunos estão pensando, o raciocínio por eles seguido e os tipos de estratégias usadas. Para isso, podem ser adotados alguns tipos de protocolos, como entrevista e questionários. Porém, há uma preferência pela observação direta do aluno com o material, porque, "mais importante do que o que os alunos respondem ou dizem é o que eles realmente fazem. Isso só se obtém pela observação” (LEFFA, 2016, p.124).

É importante, portanto, estabelecer parâmetros para a seleção dos jogos a serem utilizados em sala de aula, uma vez que, segundo Oliveira et al. (1987), "todo software educacional reflete necessariamente, uma concepção de ensino e aprendizagem, resultante de uma visão filosófica da relação sujeito-objeto".

Ao voltarem o foco para os quesitos a serem observados durante o processo de análise e escolha de softwares educacionais, Oliveira et al. (1987) elencam alguns aspectos que precisam ser considerados, tais como: a caracterização, ou seja, o conteúdo a ser trabalhado; o processo de uso; as imagens a serem apresentadas na tela; a interação entre o usuário e o jogo e a relação custo-benefício.

Quando se faz a opção por um jogo de computador com fins pedagógicos, busca-se explorar o processo de ensino-aprendizagem como um todo e, por isso, é preciso atentar para algumas características basilares que devem estar presentes. Ademais, segundo Passerino (1998), os jogos devem trabalhar com representações virtuais de maneira coerente; dispor de informações apresentadas de formas diversas (imagens, texto, sons, filmes etc.), de modo claro, objetivo e lógico; exigir concentração, coordenação e organização por parte do usuário; permitir ao usuário ver o 
resultado de sua ação de maneira imediata para facilitar a autocorreção; estimular a criatividade do usuário, incentivando-o a crescer, a tentar, sem se preocupar com os erros.

Quando a relação entre o tema de língua inglesa a ser trabalhado e os parâmetros acima apontados for observada, os jogos podem ajudar:

\begin{abstract}
o professor a criar contextos nos quais a linguagem é útil e significativa. Os alunos querem participar e para isso devem entender o que os outros estão dizendo ou escrevendo, e devem falar ou escrever para expressar seu próprio ponto de vista ou dar informação. Os jogos oferecem uma maneira de ajudar os alunos a experimentarem a linguagem ao invés de apenas estudá-la. (WRIGHT; BETTERIDGE; BUCKBY, 1998, p. 2, tradução nossa) ${ }^{1}$
\end{abstract}

Mediante o exposto, constata-se ser possível unir os conteúdos referentes ao ensino de língua inglesa aos jogos computadorizados para facilitar a assimilação de vocabulário por alunos das séries iniciais do ensino fundamental, de forma que os jogos possam ser um recurso facilitador e promovedor da aprendizagem.

\title{
METODOLOGIA
}

Para a realização deste estudo foi efetuada uma leitura bibliográfica das obras de Huizinga (2007), Kishimoto (1998), Vygotsky (1988), Wright; Betteridge; Buckb (1998) e Krashen (1982), para ampliar o conhecimento sobre o uso de jogos no processo ensino-aprendizagem de língua estrangeira, bem como conhecer quais conteúdos seriam mais propícios para o desenvolvimento de atividades com os jogos.

A seguir, foi realizada uma pesquisa de campo na Escola Municipal Vicente de Paula, localizada em Frutal/MG, por meio do oferecimento de aulas de língua inglesa aos alunos do quarto ano do ensino fundamental, os quais ainda não haviam travado contato formal com o idioma. Por essa razão, optou-se pelo trabalho com o vocabulário, uma vez que se buscava proporcionar situações em que o ensino ocorresse de forma contextualizada e significativa, por meio da interação entre os estudantes e os jogos.

Também foi efetuada uma pesquisa exploratória em sites para selecionar jogos cujos conteúdos favorecessem a aquisição de vocabulário. Foram selecionados três: Caça-palavras, Jogo da memória e Corrida dos números. A seleção levou em consideração os estudos de Wright; Betteridge; Buckby (1998) que apontam para a importância de os alunos já estarem familiarizados no seu próprio idioma com os jogos 
a serem utilizados, a fim de minimizar dificuldades. Ademais, a escolha também ocorreu devido à facilidade de interação entre o aluno, o computador e o jogo, bem como por abrangerem um amplo conteúdo lexical, como nomes de animais, frutas, cores, partes do corpo humano, números etc., além de permitirem ao usuário ver o resultado de sua ação de maneira imediata e, portanto, facilitarem a autocorreção.

A avaliação da aprendizagem foi realizada por meio da observação referentes do desempenho do aluno durante as atividades com os jogos e também pela realização de atividades de fixação, nas quais foram trabalhadas a pronúncia e a grafia das palavras. A coleta de dados foi realizada por meio de anotações, considerando o jogo a ser trabalhado, o total de acertos, o tempo utilizado para finalizar o jogo, o grau de dificuldade e a interação. Os dados coletados foram tabulados, para que se pudesse ter acesso ao percentual de aproveitamento, bem como do grau de dificuldade de interação com o jogo. Os resultados referentes ao período mencionado estão transcritos a seguir.

\section{DISCUSSÃO DOS RESULTADOS}

Com o objetivo de inserir o aluno em um conteúdo que mantivesse uma relação intrínseca com o mundo que o circunda, foi escolhido iniciar as aulas com o Jogo da memória ou Memory Game. Esse jogo foi criado na China, no século XV, e consiste em um baralho composto por cartas ilustradas com figuras. Essas figuras são duplicadas em duas cartas diferentes. Na versão física do jogo, cada jogador deve virar duas cartas e encontrar as figuras iguais. Se o par não for encontrado, as cartas são novamente viradas para baixo para que o outro participante continue o jogo. Na versão para computador, as cartas também estão com as ilustrações voltadas para o lado oposto da tela e o vencedor será aquele que encontrar os pares em um tempo menor que o dos demais participantes.

Sendo assim, foi escolhida uma versão desse jogo online, cujo conteúdo versava sobre as partes do corpo humano, mas que também permitia ao jogador ouvir e escrever o nome da figura que estava na carta, tal como mostra a figura a seguir: 
Figura 1 - Jogo da Memória.

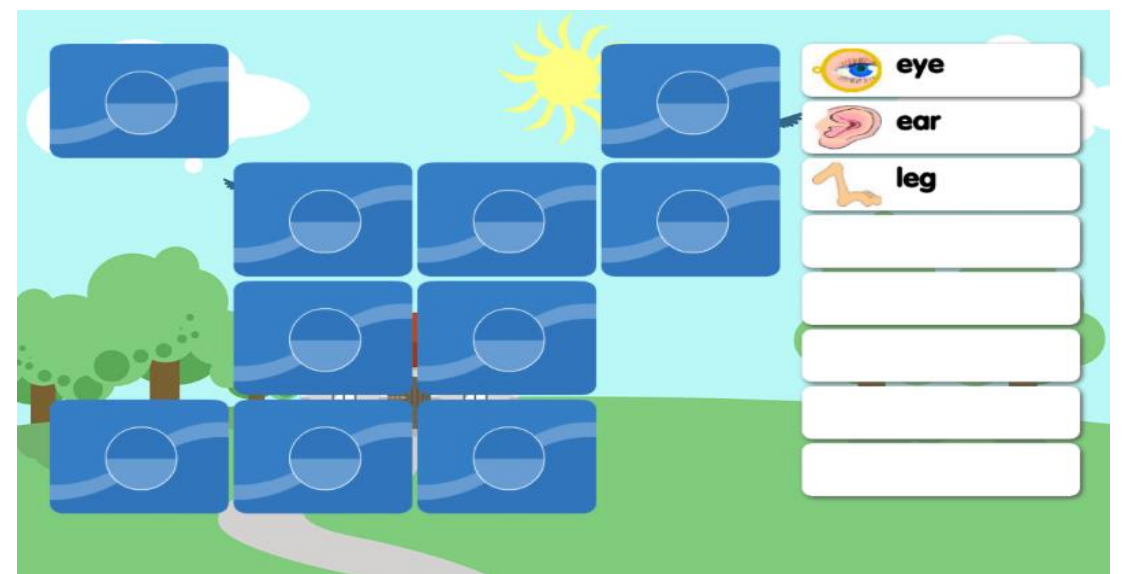

Fonte: https://www.eslgamesplus.com/body-parts-esl-vocabulary-memory- game/. Acesso em: jul.de 2020.

Neste jogo, além de explorar a grafia, a versão para computador permitiu ao aluno ouvir a pronúncia correta das palavras. Dessa forma, as habilidades de speaking, listening, reading e writing foram trabalhadas simultaneamente.

Na concepção de Krashen (1982), o vocabulário adquirido de forma natural é mais provável de ser lembrado do que aquele aprendido por meio de memorização ou uso de dicionário. Ao oferecer, em sua interface, imagens das partes do corpo humano e as palavras que as denominam, o jogo favoreceu a aquisição de vocabulário de forma natural, pois o aluno foi posto em contato direto tanto com a grafia, a pronúncia correta da palavras quanto com a imagem da parte do corpo humano correspondente a tal palavra, num contexto lúdico.

No decorrer da aula, foram avaliados o tempo gasto para finalizar o jogo, bem como a aprendizagem do vocabulário explorado. Constatou-se um aproveitamento de $80 \%$ das palavras trabalhadas.

Gráfico 1 - Total de acertos no jogo.

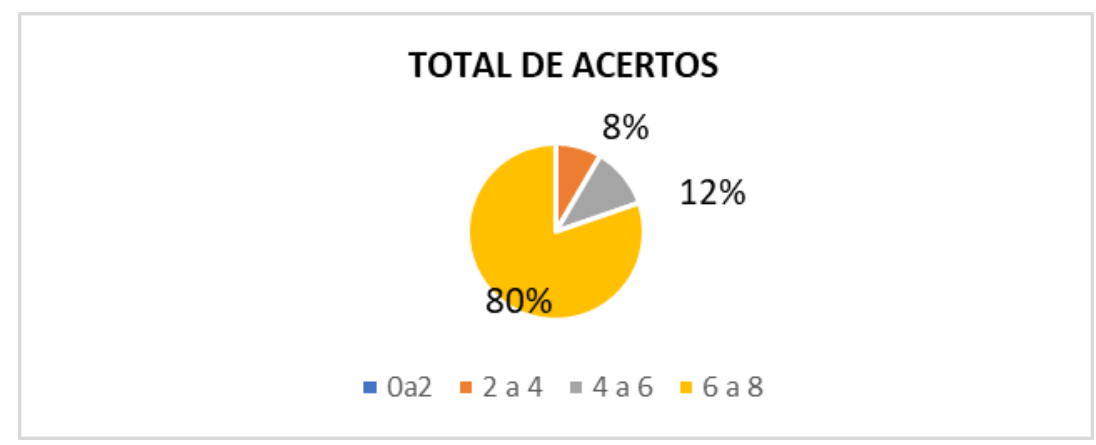

Fonte: elaborado pela autora (2020). 
E, do total de 72 alunos, $48 \%$ levaram cerca de dez a vinte minutos para encontrar os pares das cartas, compostas por imagens das partes do corpo humano, cujos nomes estavam grafados em inglês. Do total de participantes, 39\% gastaram aproximadamente de vinte a trinta minutos para encontrar todos os pares. E apenas 13\% conseguiram terminar o jogo em um tempo de dez minutos, conforme mostra o gráfico a seguir:

Gráfico 2 - Tempo gasto para jogar.

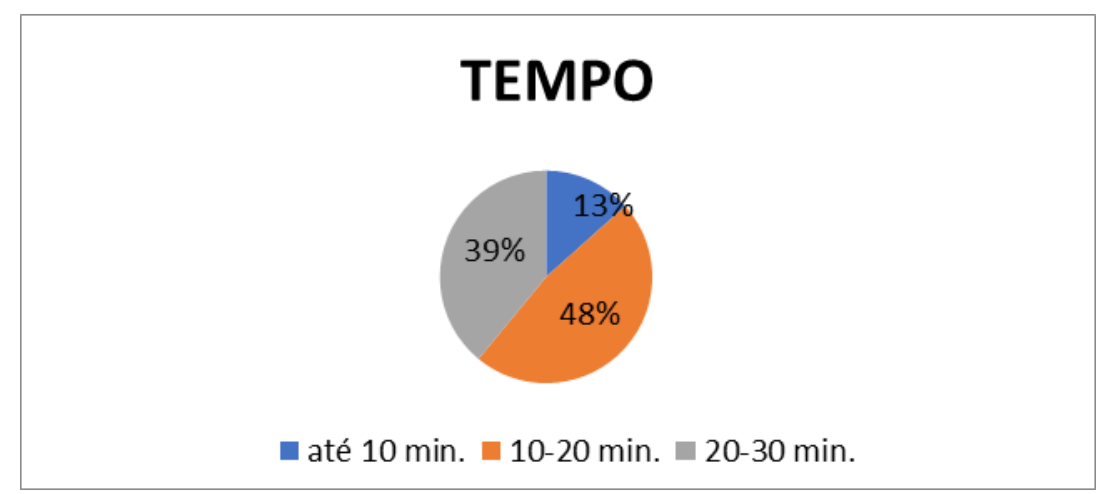

Fonte: Elaborado pela autora (2020).

Em relação à interação com o jogo, apenas $6 \%$ dos alunos responderam que não gostaram. Entre os motivos pelos quais afirmaram não gostar estão: dificuldade de memorizar os nomes das partes do corpo e pouca ação. Embora o percentual de alunos que demonstraram dificuldade de memorização seja pequeno quando comparado ao todo, trata-se de um dado relevante, porque, para esses alunos, a atividade de associar a grafia e a pronúncia da palavra com a imagem não foi suficiente para promover a aquisição do vocabulário.

Na concepção de Vygotsky (1988), a aprendizagem ocorre pela relação com o outro e pela interação social. O desenvolvimento ocorre em dois níveis: o real, isto é, aquele em que as conquistas já foram realizadas; e o potencial, que corresponde ao que a criança consegue fazer com a ajuda de outrem, ou seja, a zona de desenvolvimento proximal. Sendo assim, observa-se que o jogo em apreço não foi suficiente para promover a criação da zona de desenvolvimento proximal. Portanto, outras atividades devem ser trabalhadas para que o processo se concretize. A falta de ação descrita pelos alunos também é um aspecto que precisa ser revisto, porque o aluno pode: não ter compreendido que a ação deve partir dele ou estava esperando um jogo em que houvesse mais movimentos tanto do jogador quanto do próprio jogo. 
Gráfico 3 - Interação com o jogo

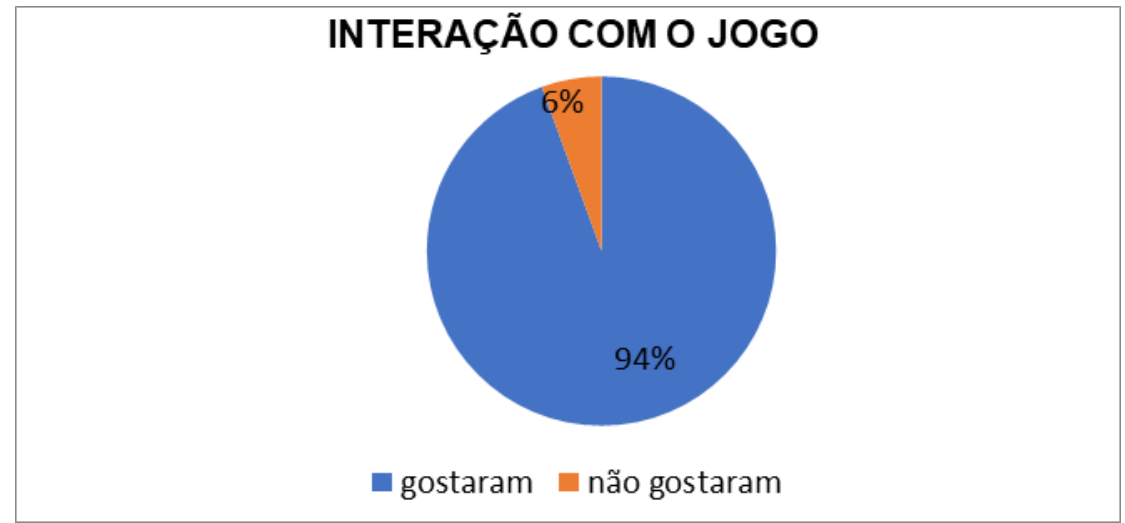

Fonte: Elaborado pela autora (2020).

Importante ressaltar que o tempo gasto para finalizar o jogo e a interação são fatores que devem ser considerados durante a escolha do jogo, porque se for muito difícil para interagir com os comandos e orientações, será preciso mais tempo para terminar a jogada. Tais fatores, consequentemente, podem desestimular o aluno.

Um dos jogos que chamou mais a atenção dos alunos foi "Corrida de Números" ou Number Race, que além de trabalhar as habilidades de reading, writing e speaking, explora também as quatro operações matemáticas (adição, subtração, multiplicação, divisão). Trata-se de um jogo que mantém um grau de proximidade com as tradicionais corridas, porém, na versão online não será por meio da explosão ou da resistência que se chegará à vitória, mas pelo raciocínio e observação.

Para jogar, formava-se uma dupla e cada integrante escolhia uma das tartarugas. Para deslocá-las, era preciso acertar o resultado da operação proposta. Por exemplo, na imagem a seguir, está disponível a soma $1+5$. O aluno tinha que saber que o resultado dessa adição é seis e que o nome desse numeral em inglês é six. Vencia a competição o membro da dupla que terminasse o percurso primeiro.

Figura 2 - Jogo Corrida dos números.

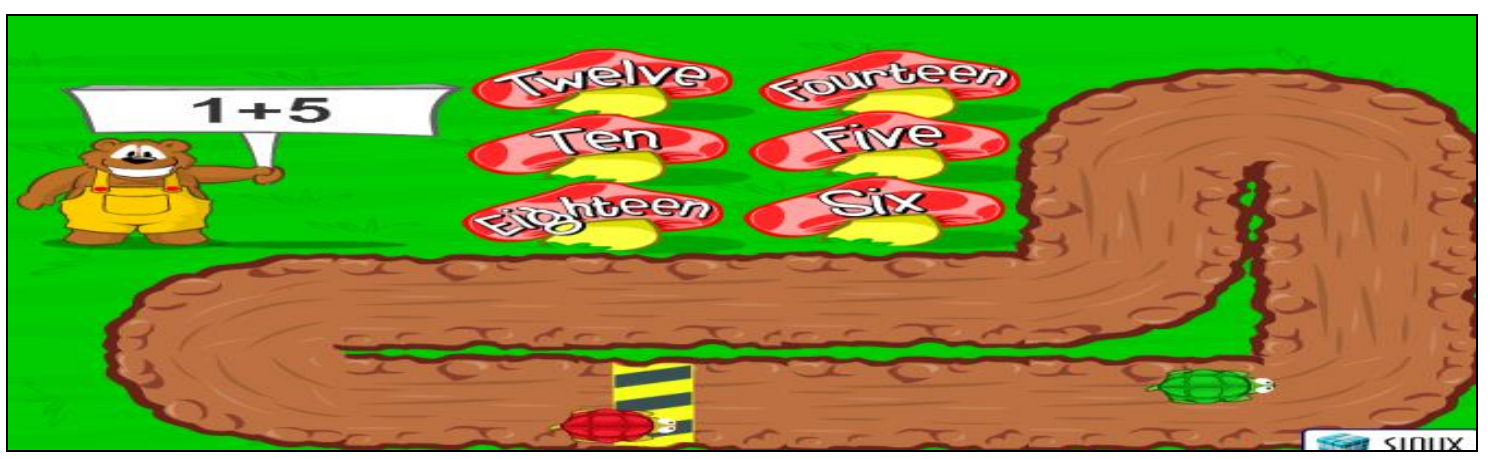


Disponível em: http://jogosonlinegratis.uol.com.br/jogoonline/aprender-ingles/.Acesso: jul. de 2020.

O percentual de aproveitamento do vocabulário, por meio desse jogo, foi de $70 \%$, tal como mostra o gráfico seguinte:

Gráfico 4 - Total de acertos no jogo.

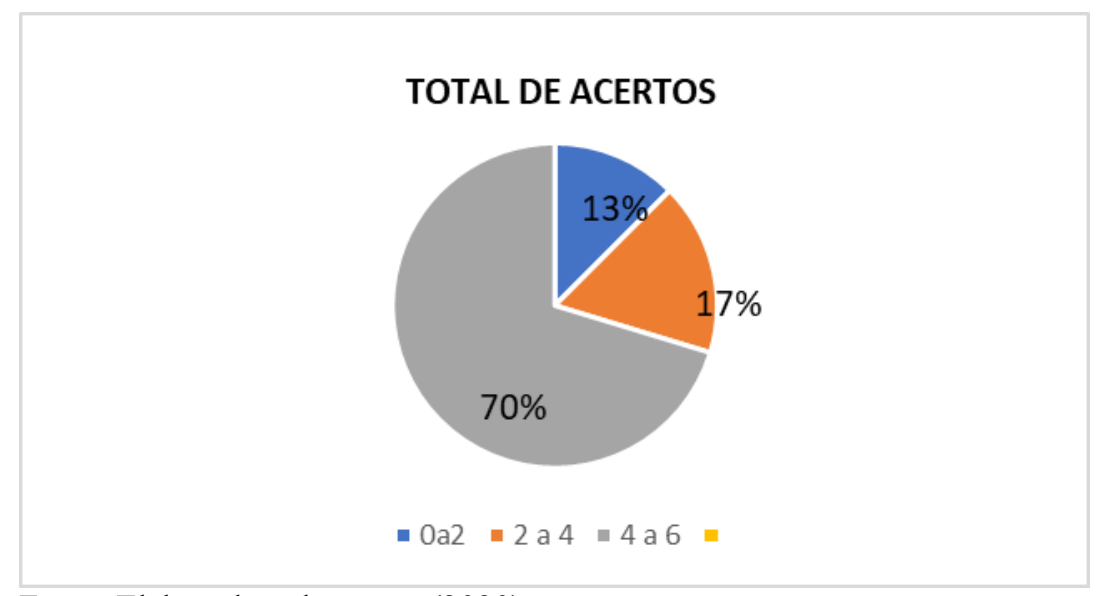

Fonte: Elaborado pela autora (2020).

Porém, para finalizar esse jogo, o tempo gasto foi maior. Cerca de $55 \%$ dos alunos precisaram de trinta minutos para terminar a atividade, uma vez que o grau de dificuldade foi maior, causado pela realização dos cálculos. Embora a dificuldade fosse maior, a interação e o interesse também foram maiores, e apenas $3 \%$ dos alunos afirmaram que não gostaram.

Na concepção de Kishimoto (1998), o trabalho com jogos requer a promoção de situações nas quais o aluno tenha a oportunidade de sistematizar a aprendizagem, uma vez que:

A utilização do jogo potencializa a exploração e construção do
conhecimento, por contar com a motivação interna, típica do lúdico, mas o
trabalho pedagógico requer a oferta de estímulos externos e a influência de
parceiros bem como a sistematização de conceitos em outras situações que
não jogos. (KISHIMOTO, 1998, p. 37-38)

Por apresentar um cenário típico do universo infantil no qual é retratada uma corrida de tartarugas, o jogo motivou os jogadores e potencializou a aquisição tanto de conhecimentos das operações matemáticas, provenientes de situações externas ao contexto do jogo, quanto de vocabulário em língua inglesa necessário para que o aluno expressasse o resultado de tais operações.

O jogo que contribuiu para a realização da atividade de avaliação de forma lúdica foi o caça-palavras ou Word-search, cuja origem remonta ao Antigo Egito. A 
versão moderna desse jogo tornou-se popular, em 1913, por meio do trabalho do jornalista Arthur Wynne. Este jogo era trabalhado na atividade subsequente à apresentação de um dos jogos contendo um vocabulário específico e versava sobre o conteúdo que já havia sido explorado em sala de aula como as partes do corpo humano, tal como mostra a figura:

Figura 3: Jogo Caça- palavras.

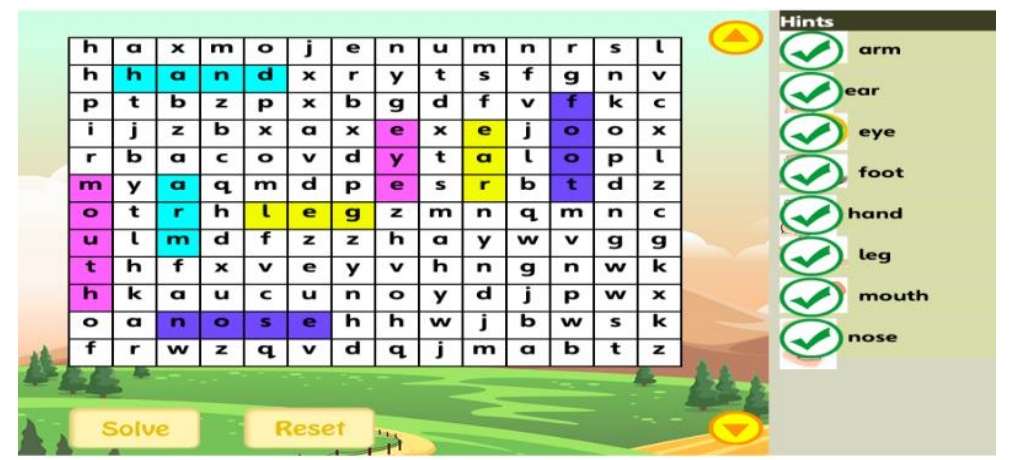

Fonte: https://www.eslgamesplus.com/body-parts-interactive-word-search/. Acesso em jul. 2020.

$\mathrm{Na}$ versão online foram acrescidos recursos sonoros que permitem ouvir a pronúncia das palavras, favorecendo o desenvolvimento da habilidade de listening associada à de speaking. Ao jogar, o aluno tinha que encontrar a palavra e, em seguida, pressionar a primeira e a última letra dela para selecioná-la, o que exigia um trabalho com a coordenação motora e também uma habilidade de reading.

Na concepção de Schimitt, "o vocabulário é aprendido gradativamente e é óbvio que isto significa que a aquisição lexical requer múltiplas exposições a uma mesma palavra" (SCHMITT, 2000, p. 137). No jogo em apreço, a mesma palavra era exposta tanto em sua forma gráfica quanto sonora e, portanto, favorecia o processo de aprendizagem dos vocábulos que foram apresentados ao aluno durante as aulas anteriores.

Por se tratar de um jogo mais "simples", ao se avaliar o grau de dificuldade, constatou-se que a maioria dos alunos teve facilidade de encontrar as palavras, perfazendo um total de $92 \%$, tal como mostra o gráfico a seguir. 
Gráfico 5 - Grau de dificuldade para jogar.

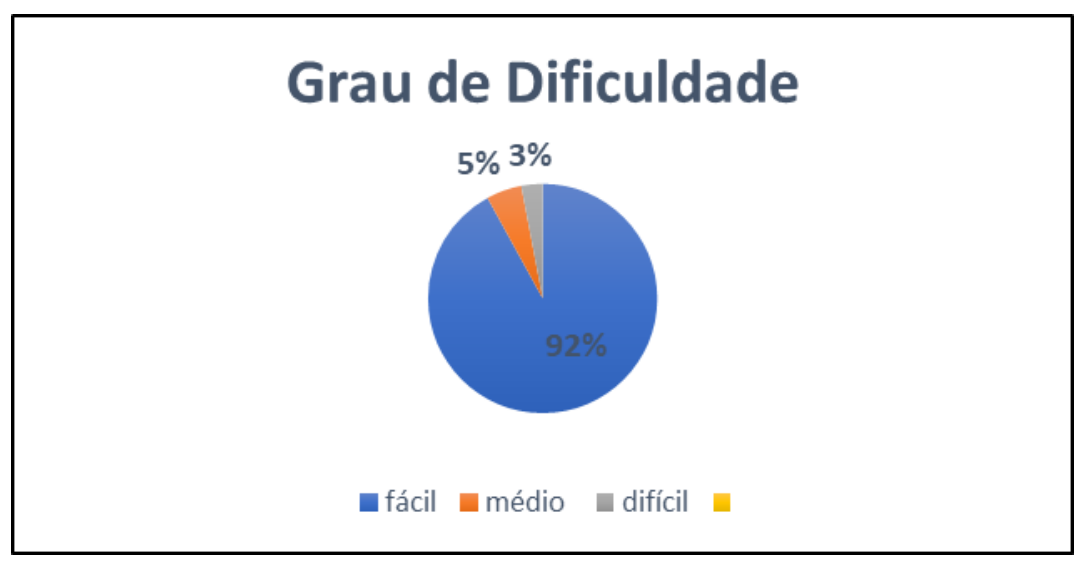

Fonte: Elaborado pela autora (2020).

A facilidade de encontrar as palavras correspondentes demonstra também um aproveitamento considerável do vocabulário trabalhado, porque o jogo exigia que o aluno prestasse atenção nas letras iniciais e finais de cada vocábulo para conseguir selecioná-lo. Trata-se de um jogo que explora a habilidade de writing e que pode ser usado para auxiliar na aquisição e memorização da grafia das sílabas das palavras.

A avalição do desempenho dos alunos durante o período de oferecimento das aulas também ocorreu de forma oral e escrita, e os resultados mostram que houve aproveitamento do vocabulário trabalhado. Segundo Leal; Albuquerque; Leite (2005), em consonância com o sistema de escrita alfabética, os jogos podem ser classificados em três tipos: jogos de análise fonológica, isto é, os que inserem atividades de análise fonológica sem fazer correspondência com a escrita; jogos que levam a refletir sobre princípios do sistema alfabético, ajudando os alunos a pensar sobre correspondências grafo-fônicas; e jogos que ajudam a sistematizar as correspondências grafo-fônicas. Sendo assim, o trabalho com os três jogos acima descritos mostrou a relevância deles para a análise fonológica e a reflexão sobre o sistema alfabético e a correspondência grafo-fônica. Além disso, as habilidades de listening, reading, writing e speaking puderam ser desenvolvidas por meio de uma atividade prazerosa e ao mesmo tempo reflexiva.

\section{CONSIDERAÇÕES FINAIS}


O trabalho com o ensino de vocabulário de língua inglesa, por meio de jogos de computador, realizado com alunos do quarto ano do ensino fundamental, demonstrou aspectos a serem observados na seleção de jogos com este fim, demonstrando como esse recurso tecnológico é uma ferramenta capaz de favorecer a assimilação de conteúdos e despertar o gosto pela aprendizagem de outros idiomas.

No que diz respeito ao estímulo e à aprendizagem de língua estrangeira, também foi possível constatar um resultado satisfatório, porque ao realizarem as avaliações para o diagnóstico da aprendizagem do vocabulário trabalhado por meio dos jogos, constatou-se que $90 \%$ dos alunos entenderam as regras dos jogos, assimilaram o vocabulário, leram, pronunciaram e escreveram palavras como nomes de frutas, animais, números e cores de forma correta. Ao término das atividades propostas, foi possível afirmar que os objetivos delineados foram alcançados, pois houve bom aproveitamento dos conteúdos trabalhados pelos discentes do quarto ano do ensino fundamental da Escola Municipal Escola Municipal Vicente de Paula, ao longo das aulas oferecidas no ano de 2017.

A avalição ocorreu de modo contínuo, tanto no que diz respeito à viabilidade do uso dos três tipos de jogos escolhidos quanto no que diz respeito ao desempenho das crianças em relação à interação com o ambiente virtual do jogo, bem como na aquisição do vocabulário. E foi possível constatar também que:

a) $\mathrm{O}$ ensino de vocabulário de língua inglesa permeado pelos jogos auxiliou na criação de um ambiente favorável ao aprendizado, uma vez que a aprendizagem se mesclou com o brincar, e o aproveitamento dos conteúdos ocorreu sem esforços, naturalmente;

b) No decorrer das aulas, houve a assimilação de cerca de $80 \%$ do vocabulário trabalhado e, à medida que percebiam o ganho de vocabulário, os alunos se tornaram mais confiantes e participativos;

c) Alunos com dificuldades de aprendizagem, ao participarem das brincadeiras e jogos, se sentiram mais estimulados para superar as dificuldades, uma vez que o trabalho de forma lúdica facilitou a socialização e a interação;

d) Quanto mais complexo era o jogo, maior era o grau de envolvimento e a participação na realização da atividade proposta. 
O trabalho com vocabulário associado aos jogos de computadores demonstrou ser uma escolha pedagógica profícua. Desataca-se ainda a contribuição desse recurso pedagógico para que o aluno perceba, ainda mais, o funcionamento da linguagem, porque:

Fazendo a linguagem transmitir informações e opiniões, os jogos fornecem os principais recursos do "drill" com a oportunidade adicional de perceber o funcionamento da linguagem como uma comunicação viva. Os jogos envolvem as emoções, e o significado da linguagem é, portanto, vividamente vivenciado. Isto é, por esse motivo, provavelmente mais bem absorvido do que o aprendizado baseado em exercícios mecânicos. (WRIGHT; BETTERIDGE; BUCKBY, 1998, p. 3, tradução nossa) ${ }^{2}$

Ao interagir com jogo, o aluno vivencia a língua em suas diferentes manifestações e aprende em situações que o aproximam do uso concreto do idioma, aspecto este que favorece o despertar do interesse e do gosto pela aprendizagem de uma língua estrangeira.

\section{Referências}

BRASIL. LEI N $N^{O}$ 9.394, DE 20 DE DEZEMBRO DE 1996. Estabelece as diretrizes e bases da educação nacional. Disponível em:

https://www2.senado.leg.br/bdsf/bitstream/handle/id/70320/65.pdf. Acesso em: 10 set. 2020.

COSTA, D. N. M. Por que ensinar língua estrangeira na escola de $1^{\circ}$ grau. São Paulo: EPU/ EDUC, 1987.

HUIZINGA, J. Homo ludens: o jogo como elemento da cultura. 5. ed. São Paulo: Perspectiva, 2007.

KISHIMOTO, T. M. O Jogo e a Educação Infantil. 2. ed. São Paulo: Pioneira, 1998.

KRASHEN, Stephen D. Principles and Practice in Second Language Acquisition. Prentice-Hall International, 1987.

LEFFA, Vilson J. Tópicos em linguística aplicada: o ensino de línguas estrangeiras. Florianópolis: Editora da UFSC, 1988, p.211-236. . Lingua estrangeira. Ensino e aprendizagem. Pelotas: EDUCAT, 2016.

LIMA, José Milton. O jogo como recurso pedagógico no contexto educacional. São Paulo: Cultura Acadêmica, 2008. 
MORAIS, Artur G. de; ALBUQUERQUE, Eliana B. C. de; LEAL, Telma F. Alfabetização: apropriação do sistema de escrita alfabética. Belo Horizonte: Autêntica, 2005.

OLIVEIRA, Celina Couto; MENEZES, Eliane Inez M.; MOREIRA, Mércia. "Avaliação de software educativo". Tecnologia Educacional. Rio de Janeiro, v.16, p. 50-54, jul./ago, 1987.

PASSERINO, L. M. “Avaliação de jogos educativos computadorizados". Taller Internacional de Software Educativo 98 - TISE' 98. Anais. Santiago, Chile, 1998. Disponível em:http://www.c5.cl/ieinvestiga/actas/tise98/html/trabajos/jogosed/. Acesso em:15 jun. 2020.

PIAGET, Jean. A psicologia da criança. Rio de Janeiro: Bertrand Brasil, 1998.

SCHMITT, N. Vocabulary in language teaching. Cambridge: Cambridge University Press, 2000.

VYGOTSKY, L. Linguagem, desenvolvimento e aprendizagem. São Paulo: Ícone/EDUSP, 1988.

Fontes, 2001. . A Construção do Pensamento e da Linguagem. São Paulo: Martins

WRIGHT, A.; BETTERIDGE, D.; BUCKBY, M. Games for Language Learning. Cambridge: University Press, 1998.

Recebido em: 31/08/2020

Aceito em: 08/12/2020

\footnotetext{
${ }^{1}$ Games also help the teacher to create contexts in which the language is useful and meaningful. The learners want to take part, and in order to do so must understand what others are saying or have written, and they must speak or write in order to express their own point of view or give information. Games provide one way of helping the learners to experience language rather than merely study it.

${ }^{2}$ By making language convey information and opinion, games provide the key features of 'drill' with the added opportunity to sense the working of language as living communication. Games involve the emotions, and the meaning of the language is thus more vividly experienced. It is, for this reason, probably better absorbed than learning based on mechanical drills.
} 